\title{
BMJ Open Incidence, course and risk factors of head injury: a retrospective cohort study
}

\author{
Herman Gerritsen, ${ }^{1}$ Mariam Samim, ${ }^{2}$ Hans Peters, ${ }^{2}$ Henk Schers, ${ }^{2}$ \\ Floris van de Laar $^{2}$
}

To cite: Gerritsen H, Samim M, Peters $\mathrm{H}$, et al. Incidence, course and risk factors of head injury: a retrospective cohort study. BMJ Open 2018;8:e020364. doi:10.1136/ bmjopen-2017-020364

- Prepublication history and additional material for this paper are available online. To view these files, please visit the journal online (http://dx.doi. org/10.1136/bmjopen-2017020364).

Received 3 November 2017 Revised 29 March 2018 Accepted 6 April 2018
Check for updates

${ }^{1}$ Primary Care Center, Geert Groote Huisartsengroepspraktijk, Zwolle, The Netherlands ${ }^{2}$ Department of Primary and Community Care, Radboud University Nijmegen Medical Centre, The Netherlands

Correspondence to Dr. Floris van de Laar; Floris.vandeLaar@radboudumc. $\mathrm{nl}$

\section{ABSTRACT}

Objectives To assess the incidence of head injury and predictors of complication across the care continuum. Design Retrospective cohort study using data from a research network. We calculated the incidence of overall head injury in a longitudinal cohort covering 1-year interval (31369 patient-years), and the incidence of complicated head injury in a longitudinal cohort covering 10 years interval (220352 patient-ears). Incidence rates were calculated per 1000 patient-years with $95 \% \mathrm{Cl}$ using the Mid-P exact test. We calculated ORs to assess potential risk factors for a complicated head injury.

Setting A practice-based research network covering a population of $>30000$ patients.

Participants All patients listed in practices within the research network during the years 2005-2014.

Main outcome measures Incidence of (complicated) head injury and predictors for clinical complications.

Results The incidence of overall head injury was 22.1 per 1000 person-years and the incidence of a complicated course following head injury was 0.16 per 1000 personyears. The following determinants were risk factors for a complicated course: high energy trauma, bicycle accident, traffic accident in general, use of anticoagulants, alcohol intoxication, age above 60 years and low Glasgow Coma Scale at initial presentation. A complicated course was very unlikely when the patients' first encounter with a healthcare professional was in primary care (OR 0.03 , $95 \% \mathrm{Cl} 0.01$ to 0.07 ).

Conclusions Complication after head injury are rarely seen in general practice. Patients who do experience complications are often easily identifiable as requiring specialist care. A more reserved referral policy for general practice may be desirable, suggesting that current guidelines are too defensive.

\section{INTRODUCTION}

Patients presenting with head injury in primary care challenge general practitioners (GPs) to differentiate between those who may be reassured, and those who are at risk of serious intracranial injury. Intracranial injuries such as epidural and subdural haematoma or skull fractures may lead to death or permanent damage if left untreated. ${ }^{1-4}$

High-quality clinical management of head injury takes the small chance of intracranial injury into account. Safe and cost-effective
Strengths and limitations of this study

Based on robust, comprehensive data set including all encounters of individual patients with healthcare professionals both from primary and secondary care.

- Scrutinous manual screening of all patients.

- Incomplete data set; use of routine data from general practice.

practice guidelines for primary care must therefore be based on a reliable risk calculation, for which precise data are needed on the incidence of both head injury and serious intracranial injury or complicated head injury. In Europe, the annual incidence of head injury presenting in hospital emergency departments (EDs) is 2.3 per 1000 person-years. ${ }^{56}$ In general practice, this incidence is expected to be higher because only a subset of patients are referred to hospital. Robust data about incidence rates in primary care are lacking. For example, a New Zealand study in a primary care population found an incidence rate of 7.5 per 1000 person-years, ${ }^{7}$ whereas, in a small pilot study in the Netherlands, we found the incidence of (mild and severe) head injury to be as high as 22.3 per 1000 person-years. ${ }^{8}$

The incidence of severe damage after a head injury is also unclear. In the UK, head injury accounts for $3.4 \%$ of all ED attendances. About $90 \%$ of head injuries in hospital setting are considered to be mild. ${ }^{67}$ Incidence of moderate-to-severe head injury was 40 per 100000 persons - a figure which may in reality be slightly higher because it does not include patients who die before admittance to the hospital. ${ }^{9}$ This makes the identification of patients at risk challenging.

Currently, guidelines for the identification, referral and management of patients with head injury at risk for intracranial damage are based on epidemiological studies from secondary or tertiary care. ${ }^{10} 11$ Currently, two different guidelines are used in the 
Netherlands, both have strong resemblance with the National Institute for Health and Care Excellence guideline as used in the UK. ${ }^{12}{ }^{13}$ It is likely that this case-mix of head injury patients is essentially different from that in primary care. ${ }^{14}{ }^{15}$ The risk for a complicated course may therefore be exaggerated, resulting in spectrum bias in current guidelines. ${ }^{14-18}$

In this study, we aim to assess the incidence of head injury across the care continuum, and to identify risk factors for intracranial injury. Our research questions were: what is the incidence of head injury and complicated head injury and what predicts a complicated course?

\section{METHODS}

\section{Study setting}

We performed a retrospective cohort study in the practice-based research network Family Medicine Network (FaMe-net) of the Department of Primary and Community Care (ELG) at the Radboud University Medical Centre. FaMe-net consists of nine Dutch general practices in three geographical regions (approximately 31000 listed patients). FaMe-net physicians systematically and prospectively register data on the reason for encounter, diagnostic procedures, diagnoses, interventions and referrals. The network uses the International Classification of Primary Care, Second Edition (ICPC-2) and International Classification of Diseases, Tenth Revision (ICD-10) classification systems to code procedures and diagnosis. All data can be linked to demographic information (age, gender, geographic location, family composition). In the Netherlands, all patients are listed in one general practice to which all encounters in secondary care are reported. Reports from other care providers are coded and linked to a new or existing episode. ${ }^{19}$ Participating doctors in FaMe-net meet on a regular basis to discuss registration issues and improve the uniformity of registration.

\section{Definitions}

We defined head injury as any trauma to the head other than superficial injuries to the face. ${ }^{13}$ A complicated head injury was defined as a head injury for which treatment and surveillance in secondary care was deemed necessary: a need for surgical intervention (defined as any neurosurgical procedure including drainage and placement of ICD), seizures in the acute post-traumatic phase, resulting neurological deficits within 12 months after trauma and death. Neurological deficits were defined as any neurological abnormalities, including facial fracture-associated nerve lesions.

\section{Study population and data collection}

We selected patients in two stages: first we performed a sensitive electronic search based on the list of ICPC labels indicating head injury (see online supplementary appendix table 1). Next, we manually scrutinised all retrieved patient records for final inclusion. In this way, we created two (retrospective) cohorts:
Cohort 1

Patients with (all types of) head injury: we expected the incidence of all head injury to be high and therefore limited the inclusion period to 1 year (between 1 January 2014 and 31 December 2014). Through a pilot study, we constructed an inclusive list of 23 diagnostic ICPC labels that (might) refer to a head injury or traumatic brain injury. For example, to refer to a head injury the code 'concussion' (N79) could be selected, and 'bruise/contusion' (S16) referring to skin involvement of the trauma (see online supplementary appendix). Next, all available clinical data from these preselected patients were manually screened for a match to our inclusion criteria of head injury. Additionally, we screened all files of deceased patients in 2014 for the cause of death to verify if head injury occurred up to 4 weeks before time of death.

\section{Cohort 2}

Patients with a complicated course: we expected complicated head injury to be rare and therefore included patients from a 10-year time interval (between 1 January 2005 and 31 December 2014). To identify patients with a complicated head injury, we used different ICPC codes that (might) refer to (consequences of) severe and complicated head injury. We also searched for specialist letters and hospital admission in the field of neurology, neurosurgery or rehabilitation medicine. All specialist letters from these preselected patients were then manually screened for a match to our inclusion criteria of head injury. In addition to specialist letters, we used GP documentation to identify known risk factors for complicated course. ${ }^{20-23}$

We reviewed all available clinical data, including general notes, hospital (including ED) correspondence, radiological imaging findings, surgical records and autopsy records. We extracted data using a predefined form (see online supplementary appendix) and excluded patients with severe multitrauma injury.

\section{Statistical analysis}

We calculated the incidence of head injury and complicated head injury per 1000 years with $95 \%$ CI, using the Mid-P exact test (Open source calculator OpenEpi, V.3). Age and sex structures of the mid-time population were used as denominators.

The incidence of head injury was defined as any new case of head injury during the study period. Some patients had more than one isolated case of head injury, each case was scored as a new finding. To determine the proportion of patients with complicated head injury, their incidence was compared with incidence of all head injuries as identified during the 1-year study period. We evaluated all included cases for demographic and trauma characteristics.

In order to assess potential risk factors for a complicated course of head injury, we calculated ORs on trauma mechanism, trauma setting, type of contact (hospital/GP/ telephonically) after trauma and patient characteristics. 
ORs were calculated using SPSS (IBM SPSS Statistics, V.22.0, Armonk, New York, USA). A p value of $<0.05$ was considered statistically significant. Multivariate regression analysis was performed on the variables gender, age and high-energy transfer (HET) - during trauma as the most relevant trauma mechanism. Factors predicting a complicated head injury were calculated by multivariate analysis with logistic regression models. Variables were age, gender, trauma mechanism, symptoms for fracture and use of anticoagulant. Moderate and severe head injury was combined during analysis due to small sample sizes. Clinical findings and data are presented using frequencies as well as percentages.

\section{RESULTS}

Incidence of all head injury

During 1-year follow-up (31 369 patient -years), we identified 694 patients with head injury (figure 1), resulting in an overall incidence rate of 22.1 per 1000 person-years

\begin{tabular}{|c|}
\hline GP registration system containing information on: \\
patient contact with GP \\
Emergency calls \\
Emergency room letters \\
Specialist letters \\
all used medication \\
\hline
\end{tabular}

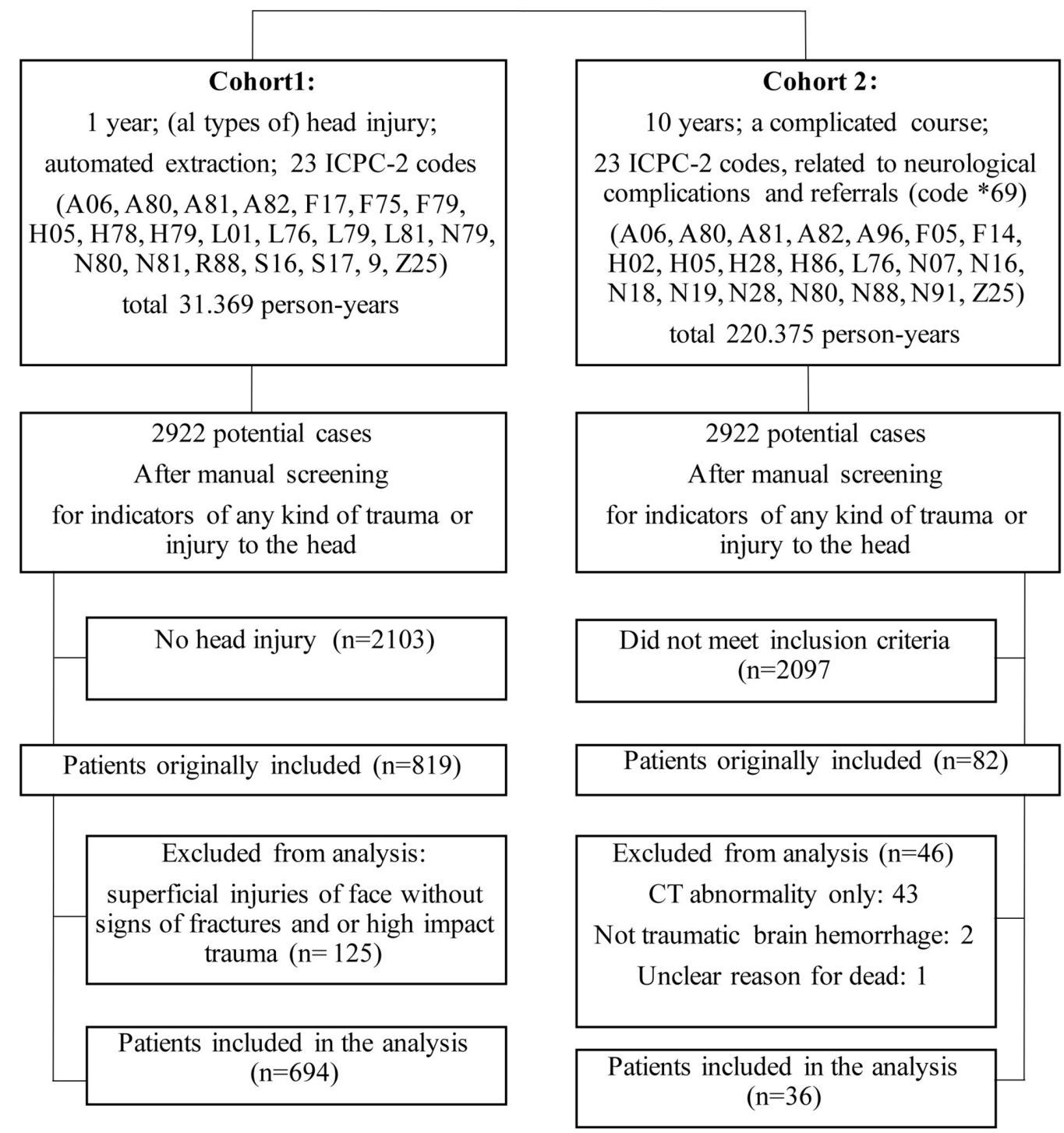

Figure 1 Study flow diagram of population in Family Medicine Network. GP, general practitioner; ICPC-2, International Classification of Primary Care, Second Edition. 
(95\% CI 20.5 to 23.8 ). The incidence rate was 123.0 per 1000 person-years (95\% CI 101.1 to 148.2 ) for children aged $0-1$ years. Out of all the patients with a head injury, $34 \%$ were under 15 years. Patient characteristics are shown in table 1.

Two of 694 patients $(0.3 \%)$ died during the study period; one was a patient aged $>90$ years who injured his head when falling from bed and died 28 days later and the other was a patient aged $>90$ years who fell against a radiator and died 1 day later. In both cases, the GP decided to renounce referral, with informed consent from patient and family, because of age and comorbidity.

Patients presenting themselves to the GP were managed without referral in $90.0 \%$ of cases $(n=546) ; 21.3 \%(n=148)$ of all head injury patients attended the hospital ED. Only $39.2 \%(n=58)$ were referred by the GP, with the remainder coming directly by ambulance or their own transport. Patients visiting the ED underwent CT scanning in 50.6\% $(n=75)$ of cases and were hospitalised for at least 24 hours in $29.7 \% \quad(n=44)$ of cases. Intracerebral lesion was seen in $6.8 \%(\mathrm{n}=10)$ of patients undergoing a CT scan; four of these patients underwent a neurosurgical intervention.

\section{Incidence of complicated head injury}

Over an observation period of 10 years we identified 36 patients with complicated head injury (220 352 patientyears), resulting in an incidence rate of 0.16 per 1000 person-years (95\% CI 0.12 to 0.22 ). Incidence rates are shown in table 2.

In $97.2 \%$ of cases, it was possible to assess the severity of traumatic brain injury from specialist correspondence. Twenty-five per cent $(n=9)$ of patients, all aged over 60 years, received anticoagulant therapy at time of head injury. No patients had a history of coagulopathies or other bleeding disorders. Most patients with a complicated head injury $(72.2 \% \quad(n=26))$ were referred directly to the hospital without involvement of a GP. If the initial contact of a complicated course was in primary care $(22.2 \%(\mathrm{n}=8))$, patients presented with severe symptoms such as neurological deficits, loss of consciousness and epilepsy. A total of eight patients (1.7\%) died during study period; two were not sent to a hospital and died without an autopsy, these were the same patients as found in cohort 1. We found out-of-hospital delay in two patients, leading to delayed neurosurgical intervention. One patient consulted his GP due to a headache without reporting that he suffered head injury 2 weeks earlier: when the headache worsened the GP referred the patient to the hospital where a subdural haematoma was diagnosed. The second patient was residing in a care home and suffering from dementia. Following a fall from bed and non-response to pain medication he was referred to hospital, where a subarachnoid haemorrhage was diagnosed.

\section{Predictors for complicated course}

Univariate regression analysis showed that an HET was related to a significantly higher risk of developing a
Table 1 Characteristics of patient and trauma

\begin{tabular}{|c|c|c|}
\hline Patient characteristics & $\begin{array}{l}\text { Cohort 1: } \\
\text { all head injury }\end{array}$ & $\begin{array}{l}\text { Cohort 2: } \\
\text { complicated } \\
\text { head injury }\end{array}$ \\
\hline Variables & $\begin{array}{l}\text { No. of patients } \\
(\%)\end{array}$ & $\begin{array}{l}\text { No. of clinical } \\
\text { complications } \\
\text { (\%) }\end{array}$ \\
\hline \multicolumn{3}{|l|}{ Gender } \\
\hline Male & $371(53.5)$ & $16(44.4)$ \\
\hline Female & $323(46.5)$ & $20(55.6)$ \\
\hline \multicolumn{3}{|l|}{ Mean age } \\
\hline All & 25.8; SD 27.7 & 58.0; SD 29 \\
\hline Male & 20.2; SD 23.6 & 48.9; SD 30 \\
\hline Female & 32.2; SD 30.5 & 65.3; SD 27 \\
\hline \multicolumn{3}{|l|}{ Presence of indicators of $\mathrm{cHI}^{*}$} \\
\hline Multiple $\mathrm{cHI}$ indicators & - & $12(33.3)$ \\
\hline Death & $2(0.3)$ & $8(22.2)$ \\
\hline Neurosurgical intervention & $4(0.6)$ & $12(33.3)$ \\
\hline Seizure & $1(0.1)$ & $6(16.7)$ \\
\hline Neurological deficit & $4(0.6)$ & $24(66.7)$ \\
\hline \multicolumn{3}{|l|}{ Current anticoagulant therapy } \\
\hline No & $642(92.5)$ & $27(75.0)$ \\
\hline Yes & $52(7.5) \dagger$ & $9(25.0) \dagger$ \\
\hline \multicolumn{3}{|l|}{ Trauma TBI classification } \\
\hline Mild & - & $26(72.2)$ \\
\hline Moderate & $3(0.4)$ & $2(5.6)$ \\
\hline Severe & $2(0.3)$ & $7(19.4)$ \\
\hline Not reported & 689 (99.3) & $1(2.8)$ \\
\hline \multicolumn{3}{|l|}{ Trauma setting } \\
\hline Home & $272(39.2)$ & $12(33.3)$ \\
\hline Work & - & $2(5.6)$ \\
\hline School/daycare & $47(6.8)$ & $2(5.6)$ \\
\hline Recreation/sport & $137(19.7)$ & $3(8.3)$ \\
\hline Traffic & $45(6.5)$ & $6(16.7)$ \\
\hline Bicycle/motor bike & $97(13.9)$ & $11(30.6)$ \\
\hline Not reported & $96(13.8)$ & - \\
\hline
\end{tabular}

Trauma mechanism

\begin{tabular}{lcc} 
Fall $>1$ m & $449(64.7)$ & $20(55.6)$ \\
HET & $52(7.5)$ & $12(33.3)$ \\
Blunt trauma & $151(21.8)$ & $2(5.6)$ \\
Acceleration/deceleration & - & - \\
Assault & $25(3.6)$ & $2(5.6)$ \\
Not reported & $15(2.2)$ & - \\
Contacts & & \\
GP only & $546(78.7)$ & $2(5.6)$ \\
Hospital only & $90(12.9)$ & $26(72.2)$ \\
GP and hospital & $58(8.4)$ & $8(22.2)$ \\
Vomiting & & \\
No & $320(46.1)$ & $10(27.8)$ \\
Yes & $54(7.8)$ & $9(25.0)$ \\
Not reported & $320(46.1)$ & $17(47.2)$ \\
\hline
\end{tabular}

Continued 


\begin{tabular}{|c|c|c|}
\hline Patient characteristics & $\begin{array}{l}\text { Cohort 1: } \\
\text { all head injury }\end{array}$ & $\begin{array}{l}\text { Cohort 2: } \\
\text { complicated } \\
\text { head injury }\end{array}$ \\
\hline Variables & $\begin{array}{l}\text { No. of patients } \\
(\%)\end{array}$ & $\begin{array}{l}\text { No. of clinical } \\
\text { complications } \\
(\%)\end{array}$ \\
\hline \multicolumn{3}{|l|}{ Neurological deficit in acute phase } \\
\hline No & $308(44.4)$ & $10(27.8)$ \\
\hline Yes & $51(7.3)$ & $21(58.3)$ \\
\hline Not reported & $335(48.3)$ & $5(13.9)$ \\
\hline \multicolumn{3}{|l|}{ Change in mental functioning } \\
\hline No & $308(44.4)$ & $10(27.8)$ \\
\hline Yes & $107(15.4)$ & $18(50.0)$ \\
\hline Not reported & $279(40.2)$ & $8(22.2)$ \\
\hline \multicolumn{3}{|l|}{ External injury } \\
\hline No & $165(23.8)$ & $7(19.4)$ \\
\hline Yes & $424(61.1)$ & $23(63.9)$ \\
\hline Not reported & $105(15.1)$ & $6(16.7)$ \\
\hline \multicolumn{3}{|l|}{ Intracranial lesions } \\
\hline No (lesions on CT scan) & $75(10.8)$ & $9(25.0)$ \\
\hline Yes (lesions on CT scan) & $10(1.4)$ & $22(61.1)$ \\
\hline Not reported or no CT scan & $609(87.8)$ & $5(13.8)$ \\
\hline \multicolumn{3}{|l|}{ If intracranial lesions on CT scan } \\
\hline Neurosurgical intervention & $4(0.6)$ & $12(33.3)$ \\
\hline No neurosurgical intervention & $6(0.9)$ & $10(27.8)$ \\
\hline
\end{tabular}

*Indicators of occurrence of $\mathrm{cHI}$.

$\dagger$ All in age group $>60$ years.

$\mathrm{cHI}$, complicated head injury; GP, general practitioner; HET, highenergy transfer; TBI, traumatic brain injury.

complicated head injury (OR $3.93,95 \%$ CI 1.97 to 7.84 ) (table 3).

Traffic and isolated bicycle accidents were also associated with a higher risk of complicated head injury (OR $2.88,95 \%$ CI 1.04 to 7.02 ), respectively (OR $2.70,95 \%$ CI 1.24 to 5.61 ). The risk of a complicated head injury was significantly reduced if the first encounter was in primary care (OR $0.03,95 \%$ CI 0.01 to 0.07 ), and conversely much higher when an ambulance was the first responder (OR $22.14,95 \%$ CI 10.6 to 48.05 ). Hospital admission without previous GP contact was related to a higher risk of complicated head injury (OR 18.04, 95\% CI 8.54 to 40.41 ). A complicated course was also seen more often with oral anticoagulants (OAC) (OR 4.10, 95\% CI 1.75 to 9.03), alcohol intoxication (OR 4.30, 95\% CI 1.38 to 11.53 ), lowering of Glasgow Coma Scale (OR 41.2, 95\% CI 16.43 to 105.00 ) and age above 60 years (OR 6.60, 95\% CI 3.30 to 13.36).

Gender, age, trauma-mechanism assault and usage of anticoagulation were included in the multivariate analysis (limited sample size precluded inclusion of further variables). We found a significantly higher risk of hospital admittance, as well as a complicated course after head injury, for age 60 years and older (OR 12.6, 95\% CI 5.0 to 31.9$)$ and the presence of symptoms that could indicate a fracture (above clavicle) (OR 2.4, 95\% CI 1.4 to 4.1). When compared with the trauma mechanism 'fall', high energetic trauma was associated with a higher risk for hospital; admission (OR 2.8, 95\% CI 1.5 to 5.2). Male gender was not found to be a predictor of a complicated course $(\mathrm{p}=0.233)$.

\section{DISCUSSION}

This is the first study to investigate the full spectrum of traumatic head injury in both primary and secondary care. We found much higher incidence rates than previously reported: 22 per 1000 patients per year, with a peak incidence in babies ( $0-1$ years) of $123 / 1000$. The incidence of a complicated head injury, on the other hand, is very low ( 0.16 per 1000 person-years) and much more in line with previous research. The vast majority of head injury patients $(78.7 \%$ ) were treated in primary care without referral, whereas the majority of patients with complicated head injury $(72 \%)$ were directly admitted to secondary care without involvement of a primary care professional. Patients with complicated injury who initially presented in primary care seemed to be easily identified and referred to secondary care, except for two patients both aged $>90$ years in which a palliative approach was chosen. Known risk factors for a complicated course such as oral anticoagulants and age above 60 years were confirmed in this study. ${ }^{21-23}$

A particular strength of our study is its setting in the Dutch healthcare system, in which all patients are registered with one particular primary care provider and all encounters with healthcare professionals reported back. This means that the primary care doctor holds an overview of all encounters with healthcare of a particular patient. ${ }^{19}$ We used the FaMe-net database, which is linked to electronic patient files in which all encounters are registered and coded. In this system, new data (encounters, letters, reports) cannot be entered without linking to a new or existing diagnosis code-making it hard to miss even the simplest case of head injury. Moreover, it is not possible to miss cases that started in primary care but were followed up elsewhere because these encounters would be reported back, registered and coded in the same file. Because the registration network has a focus on diagnosis and medical processes (eg, referrals, prescription), signs and symptoms of head injuries are registered in the same way as in any other practice. Most of the patients seen by the GPs involved simple head injuries, with no need for detailed reporting.

We found substantially higher incidence of head injury compared with existing reports. A recent systematic review on the incidence of all types of traumatic brain injury found a pooled incident rate of only 3.49 per 1000 patients per year, whereas our finding was 22 per 1000 patients per year. ${ }^{5}$ In contrast with this review, we conclude that most head injuries occur among young children-identifying incidence more than a 100 times higher in children. This 
Table 2 Incidence rates of (complicated) head injury

All head injuries $(n=694)$

Complicated head injury $(n=36)$

\begin{tabular}{|c|c|c|c|c|c|c|c|}
\hline \multirow[b]{2}{*}{$\begin{array}{l}\text { Patient } \\
\text { age and sex }\end{array}$} & \multicolumn{3}{|c|}{ Ail Hean injuries (II=084) } & \multicolumn{4}{|c|}{ 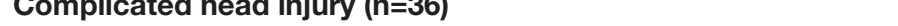 } \\
\hline & $\begin{array}{l}\text { Mid-time } \\
\text { population* }^{*}\end{array}$ & $\mathrm{HI}(\mathrm{n})$ & $\begin{array}{l}\text { Incidence rate per } 1000 \\
\text { person-years }(95 \% \mathrm{Cl})\end{array}$ & $\begin{array}{l}\text { Mid-time } \\
\text { population* }\end{array}$ & $\mathrm{cHI}(\mathrm{n})$ & $\begin{array}{l}\text { Incidence rate per } 1000 \\
\text { person-years }(95 \% \mathrm{Cl})\end{array}$ & $\begin{array}{l}\text { Proportion } \\
\text { complicated cH } \\
\text { of all } \mathrm{HI} \text { (in \%) }\end{array}$ \\
\hline 0-1 year & 418 & 54 & 129.2 (98.0 to 167.3$)$ & 3741 & 1 & 0.27 (0.01 to 1.31$)$ & 0.21 \\
\hline 2-5years & 1001 & 93 & 92.9 (75.4 to 113.3$)$ & 6708 & 1 & $0.15(0.007$ to 0.74$)$ & 0.16 \\
\hline 41-60years & 4606 & 48 & $10.4(7.8$ to 13.7$)$ & 32375 & 3 & 0.09 (0.02 to 0.25$)$ & 0.87 \\
\hline$>60$ years & 2482 & 34 & 13.7 (9.6 to 18.9$)$ & 17694 & 6 & 0.34 (0.14 to 0.71$)$ & 2.48 \\
\hline Total & 15494 & 371 & 23.9 (21.6 to 26.5 ) & 108137 & 16 & 0.15 (0.09 to 0.24$)$ & 0.63 \\
\hline \multicolumn{8}{|l|}{ Female } \\
\hline $16-40$ years & 5010 & 70 & 14.0 (11.0 to 17.6$)$ & 34546 & 0 & $0(-)$ & 0 \\
\hline $41-60$ years & 4550 & 37 & 8.1 (5.8 to 11.1$)$ & 32265 & 3 & $0.09(0.024$ to 0.25$)$ & 1.11 \\
\hline$>60$ years & 2826 & 79 & 28.0 (22.3 to 34.7$)$ & 21531 & 14 & 0.65 (0.37 to 1.07$)$ & 2.32 \\
\hline Total & 15875 & 323 & 20.4 (18.2 to 22.7 ) & 112238 & 20 & $0.18(0.11$ to 0.27$)$ & 0.88 \\
\hline \multicolumn{8}{|l|}{ Male and female } \\
\hline $0-1$ year & 854 & 105 & $123.0(101.1$ to 148.2$)$ & 7391 & 1 & 0.14 (0.006 to 0.67$)$ & 0.11 \\
\hline 2-5years & 1950 & 134 & 68.7 (57.8 to 81.1$)$ & 12827 & 2 & $0.16(0.026$ to 0.52$)$ & 0.23 \\
\hline $6-15$ years & 4413 & 134 & 30.4 (25.5 to 35.9$)$ & 29262 & 3 & 0.10 (0.03 to 0.28$)$ & 0.33 \\
\hline 16-40years & 9688 & 123 & 12.7 (10.6 to 15.1$)$ & 67030 & 4 & 0.06 (0.02 to 0.14$)$ & 0.47 \\
\hline
\end{tabular}

*Mid-time population is calculated by means of total patient population on 1 January and 31 December.

$\mathrm{cHI}$, complicated head injury.

difference might be explained by variable classification, especially since the systematic review's authors point out the problem of non-standardised reporting among neuroepidemiological studies on incidence of (particularly mild) head injury. One particular study claimed to assess the full spectrum of head injury by including data from general practice, resulting in an incidence of 7.90 per 1000 patients per year. Unfortunately, this study limited inclusion to patients with head injury and 'physiological disruption of brain function'. ${ }^{7}$

Variation in definition of head injury is an ongoing problem in current literature, resulting in a wide range of incidence figures of traumatic head injury. ${ }^{54-26}$ One particular review stated that the term 'silent epidemic' could be used to characterise the incidence of head injury, because many cases are not recognised and therefore excluded from official statistics. ${ }^{26}$ Our study captures the full spectrum of head injury as presented in the entire healthcare system (in and out of hospital) with inclusion based on any trauma of the head excluding injuries of the face. This is in line with current guidelines for primary care that apply a similar broad definition of head trauma. We fully endorse this broad definition for future diagnostic and prognostic research aimed at primary care populations. The nature of primary care is that it is easily and rapidly accessible for every patient with no preselection or other thresholds. Even in primary care it is difficult to rule out a complicated course. After all, the condition was (per definition) sufficiently severe for patient, parents or bystanders to seek professional help. Moreover, neurological indications may not develop in this early stage so a definition based on signs of 'disruption of brain function'-as has previously been advocated-is not feasible. ${ }^{26}$ We are furthermore convinced that identifying patients with mild trauma (including those not seen in a hospital setting) is relevant because (un-)complicated head injury may still be associated with significant cost in terms of disability, lost work or neuropsychiatric complications. ${ }^{27} 28$ 
Table 3 Univariate regression analysis for complicated head injury

\begin{tabular}{|c|c|c|c|}
\hline Variable & OR $^{*}$ & $95 \% \mathrm{Cl}$ (mid-P exact) & $\begin{array}{l}P \text { values (two-tailed mid-P } \\
\text { exact) }\end{array}$ \\
\hline \multicolumn{4}{|l|}{ Trauma mechanism } \\
\hline HET & 3.93 & 1.97 to 7.84 & $<0.000$ \\
\hline Car vs pedestrian/bicycle & 1.709 & 0.24 to 7.90 & 0.5134 \\
\hline Fall >1 m & 1.029 & 0.35 to 2.69 & 0.9307 \\
\hline High impact & 1.285 & 0.47 to 3.24 & 0.5935 \\
\hline Fall & 0.68 & 0.35 to 1.37 & 0.2767 \\
\hline \multicolumn{4}{|l|}{ Trauma setting } \\
\hline Home & 0.78 & 0.37 to 1.57 & 0.493 \\
\hline Work & 1.301 & 0.20 to 4.91 & 0.682 \\
\hline School & 0.81 & 0.13 to 2.98 & 0.846 \\
\hline Rec/sport & 0.37 & 0.09 to 1.11 & 0.080 \\
\hline Traffic & 2.88 & 1.04 to 7.02 & 0.042 \\
\hline Bicycle & 2.70 & 1.24 to 5.61 & 0.014 \\
\hline \multicolumn{4}{|l|}{ Contacts } \\
\hline First encounter GP & 0.03 & 0.01 to 0.07 & $<0.000$ \\
\hline First encounter ambulance & 22.14 & 10.60 to 48.05 & $<0.000$ \\
\hline GP only & 0.02 & 0.00 to 0.06 & $<0.000$ \\
\hline Hospital only & 18.04 & 8.54 to 40.41 & $<0.000$ \\
\hline GP/hospital & 3.15 & 1.29 to 7.07 & 0.0138 \\
\hline \multicolumn{4}{|l|}{ Patient characteristics } \\
\hline Use of OAC & 4.10 & 1.75 to 9.03 & 0.002 \\
\hline Alcohol intoxication & 4.30 & 1.38 to 11.53 & 0.015 \\
\hline GCS $<12$ (excl. not reported) & 41.2 & 16.43 to 105.00 & 0.000 \\
\hline Male gender & 0.69 & 0.35 to 1.37 & 0.292 \\
\hline Age $>60$ years & 6.60 & 3.30 to 13.36 & $<0.000$ \\
\hline Age groups $\uparrow$ & & & $<0.000$ \\
\hline 0-1 year (reference group) & - & - & - \\
\hline $2-5$ years & 1.58 & 0.14 to 17.65 & 0.711 \\
\hline $6-15$ years & 2.37 & 0.24 to 23.10 & 0.458 \\
\hline 16-40years & 3.42 & 0.38 to 31.02 & 0.275 \\
\hline $41-60$ years & 7.50 & 0.89 to 63.51 & 0.065 \\
\hline$>60$ years & 19.27 & 2.5 to 146.13 & 0.004 \\
\hline
\end{tabular}

${ }^{*}$ ORs are based on conditional maximum likelihood estimate.

†Significances of OR calculated are in relation to youngest age group.

GCS,Glasgow Coma Scale; GP, general practitioner; HET, high-energy transfer; OAC, oral anticoagulants.

Although existing guidelines are based on a broad definition of head injury, the underlying evidence is based almost exclusively on clinical populations. In clinical populations, a (self-)selection for complicated head injury has already taken place and a narrow definition of head injury is used, ${ }^{1011132930}$ leading to a higher estimated risk for complications and overtreatment of patients with head injury. 31

We conclude that head injury as seen in primary care comprises an essentially different case-mix as compared with secondary care. Moreover, complicated cases appear to be easily identified and readily presented to secondary care. Our study requires confirmation in other settings using other databases, but we are convinced that current guidelines are based on limited evidence of true incidence rates. This makes them prone to spectrum bias. A more reserved management of head injury in primary care should be considered, leading to more cost-effective use of costly hospital diagnostic resources. This study also calls for an internationally accepted definition (coupled 
with a universal diagnostic algorithm) of head injury and (mild) traumatic brain injury.

Contributors HG, MS, HP, HS, FvdL was involved and made contributions in the design of the study, acquisition, analysis and interpretation of the data. GH: drafted the work and revised it critically for important intellectual content. MS, HP, HS, FvdL: revised the work critically for important intellectual content. HG, MS, HP, HS, FvdL: gave final approval of the version published and made agreement to be accountable for all aspects of the work in ensuring that questions related to the accuracy or integrity of any part of the work are appropriately investigated and resolved.

Funding The Hein Hogerzeil foundation funded the article publishing fee in the form of a grant.

Competing interests None declared.

Patient consent Not required.

Provenance and peer review Not commissioned; externally peer reviewed.

Data sharing statement No data of this study are made available otherwise than in this submission.

Open Access This is an Open Access article distributed in accordance with the Creative Commons Attribution Non Commercial (CC BY-NC 4.0) license, which permits others to distribute, remix, adapt, build upon this work non-commercially, and license their derivative works on different terms, provided the original work is properly cited and the use is non-commercial. See: http://creativecommons.org/ licenses/by-nc/4.0/

(C) Article author(s) (or their employer(s) unless otherwise stated in the text of the article) 2018. All rights reserved. No commercial use is permitted unless otherwise expressly granted.

\section{REFERENCES}

1. Langlois JA, Rutland-Brown W, Wald MM. The epidemiology and impact of traumatic brain injury: a brief overview. J Head Trauma Rehabil 2006;21:375-8.

2. Rimel RW, Giordani B, Barth JT, et al. Disability caused by minor head injury. Neurosurgery 1981;9:221-8.

3. Anon. Rehabilitation of persons with traumatic brain injury. NIH Consens Statement 1998;16:1-41.

4. Rose VL. NIH issues consensus statement on the rehabilitation of persons with traumatic brain injury. Am Fam Physician 1999;59:1051-3.

5. Nguyen R, Fiest KM, McChesney J, et al. The International Incidence of Traumatic Brain Injury: A Systematic Review and Meta-Analysis. Can J Neurol Sci 2016;43:774-85.

6. Tagliaferri F, Compagnone C, Korsic M, et al. A systematic review of brain injury epidemiology in Europe. Acta Neurochir 2006;148:255-68.

7. Feigin VL, Theadom A, Barker-Collo S, et al. Incidence of traumatic brain injury in New Zealand: a population-based study. Lancet Neurol 2013;12:53-64.

8. Gerritsen H, Schers H, van de Laar F. Incidentie hoofdtrauma: hoger dan gedacht. Huisarts Wet 2015;58:80-1.

9. Gardner AJ, Zafonte R. Neuroepidemiology of traumatic brain injury. Handb Clin Neurol 2016;138:207-23.
10. de Kruijk JR, Nederkoorn PJ, Reijners EP, et al. [Revised practice guideline 'Management of patients with mild traumatic head/brain injury']. Ned Tijdschr Geneeskd 2012;156:A4195.

11. Opstelten W, Goudswaard AN. [Revised practice guideline on mild traumatic head/brain injury: mainly for secondary care]. Ned Tijdschr Geneeskd 2012;156:A4474

12. Draijer LW, Kurver MJ, Opstelten W. [The NHG practice guideline 'Head injury']. Ned Tijdschr Geneeskd 2015;159:A8992.

13. National Clinical Guideline C. National Institute for Health and Clinical Excellence: Guidance. Head Injury: Triage, Assessment, Investigation and Early Management of Head Injury in Children, Young People and Adults. London: National Institute for Health and Care Excellence (UK) Copyright (c) National Clinical Guideline Centre, 2014.

14. Knottnerus JA. Interpretation of diagnostic data: an unexplored field in general practice. J R Coll Gen Pract 1985;35:270-4.

15. Jelinek M. Spectrum bias: why generalists and specialists do not connect. Evid Based Med 2008;13:132-3.

16. Ransohoff DF, Feinstein AR. Problems of spectrum and bias in evaluating the efficacy of diagnostic tests. $N$ Engl J Med 1978;299:926-30.

17. Whiting PF, Davenport C, Jameson C, et al. How well do health professionals interpret diagnostic information? A systematic review. BMJ Open 2015;5:e008155.

18. Willis $\mathrm{BH}$. Spectrum bias--why clinicians need to be cautious when applying diagnostic test studies. Fam Pract 2008;25:390-6.

19. van Weel $\mathrm{C}$, Schers $\mathrm{H}$, Timmermans $A$. Health care in the Netherlands. J Am Board Fam Med 2012;25(Suppl 1):S12-17.

20. Pandor A, Harnan S, Goodacre S, et al. Diagnostic accuracy of clinical characteristics for identifying CT abnormality after minor brain injury: a systematic review and meta-analysis. J Neurotrauma 2012;29:707-18.

21. Smits M, Dippel DW, de Haan GG, et al. External validation of the Canadian CT Head Rule and the New Orleans Criteria for CT scanning in patients with minor head injury. JAMA 2005;294:1519-25.

22. Smits M, Dippel DW, Steyerberg EW, et al. Predicting intracranial traumatic findings on computed tomography in patients with minor head injury: the CHIP prediction rule. Ann Intern Med 2007;146:397-405

23. Stiell IG, Wells GA, Vandemheen K, et al. The Canadian CT Head Rule for patients with minor head injury. Lancet 2001;357:1391-6.

24. Peeters W, van den Brande R, Polinder S, et al. Epidemiology of traumatic brain injury in Europe. Acta Neurochir 2015;157:1683-96.

25. Brazinova A, Rehorcikova V, Taylor MS, et al. Epidemiology of Traumatic Brain Injury in Europe: A Living Systematic Review. J Neurotrauma 2016

26. Rusnak M. Traumatic brain injury: Giving voice to a silent epidemic Nat Rev Neurol 2013;9:186-7.

27. DeKosky ST, Blennow K, Ikonomovic MD, et al. Acute and chronic traumatic encephalopathies: pathogenesis and biomarkers. Nat Rev Neurol 2013;9:192-200.

28. Thurman DJ. The Epidemiology of Traumatic Brain Injury in Children and Youths: A Review of Research Since 1990. J Child Neurol 2016;31:20-7.

29. N-w H. The Dutch College of General Practitioners' guideline Head injury. Huisarts Wet 2015;58:82-8.

30. Van der Kruijk RA. Guideline for the managment of patients with mild headtrauma, proposal for interim adjustment. Tijdschr Neurolog \& Neurochi 2015;116:154-8.

31. van den Brand CL, Rambach AH, Postma R, et al. [Practice guideline 'Management of patients with mild traumatic head/brain injury' in the Netherlands]. Ned Tijdschr Geneeskd 2014;158:A6973. 